\title{
Co-creation Pathway for Urban Nature-Based Solutions: Testing a Shared-Governance Approach in Three Cities and Nine Action Labs
}

\author{
Israa Mahmoud and Eugenio Morello
}

\begin{abstract}
Nature-based solutions (NBS) implementation in urban contexts has proven outcoming multiple benefits to reverse the current trend of natural resources' degradation adversely affecting biodiversity, human health, and wellbeing. Yet, the current urban-planning policy frameworks present a rigid structure to integrate NBS definitions, and their co-benefits to get mainstreamed and up scaled on a wider urban spatial dimension. In this research, we test a complete co-creation pathway that encourages decision-makers to embed citizen engagement methodologies as an approach to co-design and co-implement NBS in shared-governance processes aiming to increment the greening of urban spaces, towards more inclusive and climate resilient cities. On one hand, we assess a tendency to involve a multiplicity of stakeholders that collaborate to the establishment of an Urban Innovation Partnership (UIP) aiming at increasing the social awareness around NBS themes, and at the same time tackling both financial and governance aspects. On the other hand, the innovation embedded in NBS paves the way to combine a multi-scalar flexibility in implementation tools and place-based urban actions, hence resulting in widespread economic, environmental, and social impacts in place. The novelty in embedding the co-creation process in urban-planning practice lies in catalyzing resources towards the transposition of research into practice through policy and planning tools for local authorities and decision-makers. Three front-runner cities (Hamburg, London, and Milan) are under investigation as part of Clever Cities - a Horizon 2020 projectaiming at implementing NBS in diverse urban-regeneration processes, through nine up-running Urban Living Labs (ULLs). Grounded on a comparative analysis of these three cities, key characterization for NBS implementation framework could be categorized into: (1) current urban-planning greening strategies in each context, (2) specific environmental and societal challenges addressed, (3) different typologies and scales of NBS integration within urban morphologies, (4) specific governance
\end{abstract}

\footnotetext{
I. Mahmoud ( $\square) \cdot$ E. Morello

Laboratorio di Simulazione Urbana Fausto Curti, Dipartimento di Architettura e Studi Urbani,

Politecnico di Milano, via Bonardi 3, 20133 Milano, Italy

e-mail: Israa.mahmoud@polimi.it

URL: http://www.labsimurb.polimi.it/

E. Morello

e-mail: Eugenio.morello@polimi.it
}

(C) The Author(s) 2021

A. Bisello et al. (eds.), Smart and Sustainable Planning for Cities and Regions, Green Energy and Technology, https://doi.org/10.1007/978-3-030-57764-3_17 
process as response to co-design and co-implementation processes, and (5) availability of financial investment and main stakeholders. As research results, we emphasize using co-creation approach in urban planning to embed and upscale NBS in an inclusive shared-governance process, hence contributing to social awareness and acceptance. Meanwhile, spatial, and financial challenges could be majorly resolved using a multi-scalar approach to manage newly embedded urban-greening policies at the urban level. Lastly, the implementation scale of NBS with local communities requires a radical paradigmatic shift in societal, individual and administrative urban-planning practices.

Keywords Nature-based solutions · Co-creation · Shared governance $\cdot$ Urban regeneration $\cdot$ Urban living labs

\section{Introduction}

While the environmental policy and governance research around nature-based solutions (NBS) are currently under discussion, the implementation of green measures has taken a leap forward, proliferating in a diversity of urban contexts. That is mainly due to European Commission accelerated funds in Horizon 2020 program (European Commission 2015). Nonetheless, the academic domain has raced to catch-up with advanced major endeavors to utilize the NBS umbrella concept of ecosystem-based approaches to address sustainability challenges, such as resources shortages and flood and heat risks, as well as climate-change adaptation and mitigation aspects (Albert et al. 2019; Cohen-Shacham et al. 2019; Lafortezza and Sanesi 2019). The focus on NBS as a potential topic for research and innovation in urban-regeneration processes was identified by the European Commission (2015: 4) to address four fundamental goals: (1) enhancing sustainable urbanization; (2) restoring degraded ecosystems; (3) developing climate-change adaptation and mitigation; and (4) improving risk management and resilience in urban settings (Bourguignon 2017; Raymond et al. 2017).

This research originates as part of the Clever Cities ${ }^{1}$ project, which investigates and implements NBS to address urban challenges and promote social inclusion in nine cities across Europe, South America, and China. Three cities are the frontrunners in the experimental processes: Hamburg, London, and Milan and other six cities are to follow with NBS implementation. Starting from this wide research scope, the present research work aims at testing the methodological scientific effectiveness of co-creation and shared-governance approaches specifically developed for Clever Cities and nine Urban Living Labs (ULLs), called Clever Action Labs (CALs). In particular, this study is divided in three main parts: (a) the co-creation concept explanation and principles of implementation; (b) the methodology to adopt NBS in CALs; and (c) a comparative analysis of co-creation process results as initiated by

\footnotetext{
${ }^{1}$ A European Commission funded project from the Horizon 2020 Innovation Action Programme under Grant Agreement No. 776604. See https://clevercities.eu/.
} 
Clever Cities. The first part analyzes in depth the ongoing co-creation processes, its theoretical inception and possible correlation with urban regeneration to implement the NBS concept within the wider scope of the project. The second part compares the nine CALs co-creation pathways of NBS within urban-regeneration processes, while testing citizen engagement toolkits and an inclusive shared-governance approach. The last part reflects on the lessons learned from the co-creation process and urbanregeneration challenges addressed by NBS in place.

While the relevance is evident for using NBS in solving sustainable urbanization issues and climate- change pressures, there is no denying that there is an emerging need to embed a more citizen-oriented engagement approach within its' implementation (Gudowsky and Peissl 2016; Sanders and Stappers 2008). The literature emphasizes the radical role of a shared process with a multi-scalar stakeholder partnerships to increment the greening potential of urban spaces towards more inclusive and climate resilient cities (Bason 2010; Bisschops and Beunen 2019; Jansen and Pieters 2017; Leith et al. 2014; Puerari et al. 2018). Hence, we opted for testing a complete co-creation pathway that supports decision- and policy-makers towards embedding co-design, co-implementation, co-monitoring and co-development of NBS during the whole process (see Clever Cities Guidance in (Morello et al. (2018)).

Co-creation is not a novel concept; however, incorporating co-creation in CALs to implement NBS required a solid initiative from the three city authorities for getting accustomed to a shared-governance approach based on open participation and citizen empowerment. Accordingly, the novelty in applying co-creation in urban-greening projects has a threefold aim: firstly, to enhance the awareness and knowledge of citizens and stakeholders around NBS and their co-benefits; secondly, to enhance inclusivity in decision-making for urban transformation, hence, accelerating the need for capacity building in public administration towards an effective shared governance; and thirdly, to achieve a better quality of the regeneration interventions, emerging as the results of site-specific processes that build on the continuous improvement cycles and design-thinking stages during the various co-creation phases (DeLosRíos-White et al. 2020).

In the first 20 months from June 2018 until January 2020, nine ULLs were setup, and numerous stakeholders and partners were actively involved. Here, we depict the current status of the co-creation experiences and bottlenecks faced by the cities during the establishment of the UIP and partially during the initiation of the co-design phases in the CALs. Hence, we propose the use of the co-creation methodology as a catalyst and a driver to respond to the urgent climate-change adaptation and mitigation challenges, pressuring health and well-being, social and economic aspects. We mainly argue about the motivation of stakeholders' multiplicity for adopting a cocreation approach towards NBS implementation in cities, as well as the multiscalar spatial impacts observed added values into urban-regeneration processes. 


\section{Framework of Co-creation: Characteristics and Implementation in Urban-Regeneration Contexts}

\subsection{Co-creation in Theory: Definition and Added Values}

Co-creation arose from the business world as "the practice of collaborative product or service development: where developers and stakeholders are working together" (Pater 2009; Prahalad and Ramaswamy 2004; Ramaswamy and Ozcan 2018). Bason (2010: 6) referred to co-creation as the "systematic process of creating new solutions with people-not for them; involving citizens and communities in policy and service development." Until recently, these two definitions remain grounded in the academic literature as a common framework to integrate co-production of knowledge intertwined with the co-design of solutions based on implementation cases: definitions, outcomes, and joint framing of social problems with stakeholders (Agrawal et al. 2015; Burkett 2016; Mauser et al. 2013).

Bason (2013: 26) alerted European Commission expert group on public sector innovation to the need to embed co-design and co-creation of innovative solutions. This could be worked out within governments, non-governmental sector, businesses, third sector and citizens as the main experts to orchestrate the design-driven processes of organizational learning and institutional innovations. A new EC project on fostering territorial innovation for climate action (TeRRIFICA 2019)3F calls for adopting co-creation as a form of collaborative social innovation wherein ideas are shared and improved together rather than kept to oneself. As a matter of fact, co-creation could also be seen as a living concept for an active involvement of actors during the processes of knowledge production and the design of engaged solutions. In addition, stakeholders and academic institutional involvement along the process are regarded through the lens of sectoral integration, with the ambition of transforming decision-making processes into flexible learning processes that bring together multiple actors and knowledge practitioners to jointly produce a mutually valued outcome (Galafassi et al. 2018; Parsons et al. 2016).

Throughout the pathway, partners explore the benefits of cooperating and highlighting mutual strengths, making the whole process more efficient and leading to better outcomes. The collaborative dialogue is not designed to force compromises, but rather to facilitate learning and build on harmonizing strengths and assets. Nonetheless, the need for multiple stakeholders to join forces and craft effective responses highlights the unusually important role of social science in the analysis of urban resilience. As an example, each partner brings different expertise: some know more about the area, others about the people and their daily experiences, and others about the local challenges for technical NBS implementation aspects. In other words, successful solutions to environmental problems in urban areas using a complete cocreation process require the combined efforts of different scientific disciplines and active dialogues between stakeholders from policy and practice actors (Frantzeskaki and Kabisch 2016). Hence, we conclude that instead of the traditional hierarchical organization structure, co-creation goes beyond common participatory methods to 
develop innovative solutions for complex (environmental/social/economic) problems in cities.

In fact, when it comes to urban regeneration, co-creation shifts the focus from centralized governance towards a more shared decision-making approach by empowering local civic actors and encouraging strong partnerships (McCormick and Kiss 2019; Rock et al. 2018). However, the concept remains fuzzy since it was not "putinto-practice" enough times to triangulate and evaluate if co-creation really leverages the possible outcomes on the long-run and has a transformative added values effects, especially on the urban-planning policies scale (Bisschops and Beunen 2019; Gudowsky and Peissl 2016). Academic research pinpoints some fundamental principles of implementation that amplify the circle of co-creation such as (1) adequate tools for citizen engagement (Engage 2020, 2015; Serrano Sanz et al. 2014); and (2) stakeholder collaboration in a flexibly structured process5 (Wippoo and van Dijk 2019).

Another important aspect in co-creation implementation principles is that it needs to harness a spatial context; co-creation does not occur if there is no "real problem" to solve; in urban regeneration, this is called place-based approach. Yet, scientific experiences are rushing to set out guidelines and principles to make co-creation principles more feasible to local governments, policy-makers, and practitioners, to be embedded in urban-regeneration processes (Jansen and Pieters 2017). Hence, the research question lingers on how to embed co-creation principles in cities' complex and sophisticated urban reality, whereas stakeholders run their agendas separately, resources are scarce, and land availability is limited. What's more, if we have specific guidelines to get co-creation done right, what are the main principles and rules to get co-creation done inclusively?

Lastly, the co-creation process does not have a one-size fits-all approach (Wippoo and van Dijk 2019: 8). Understanding pathway structure and sleeve tools are important to undertake the practical aspects of co-creation facilitation towards implementation, especially that each co-creation process is unique; and theoretical frameworks do not necessarily mirror co-creation in reality. Co-creation, therefore, needs a medium to get implemented and a flexible operational structure to be optimally concluded. Nonetheless, the co-creation effectiveness and efficiency of results relies on the implementation of each pathway based on attained outcomes and intermediate milestones. As a consequence, the paradigm shift accompanying co-creation somehow "unavoidably" occurs and shifts the organizational hierarchy of local governments and institutional structures towards integrated management and shared responsibility (Leroy and Arts 2006). 


\subsection{Co-creation in Practice and Urban Living Labs Experiences}

From the recent literature on how co-creation supports inclusive design of long-term solutions, it is evident that co-creation is a way to cope with the complexity and uncertainty that NBS have added for delivering results on sustainability measures and resilience programs (Frantzeskaki 2019; Lawrence et al. 2013). This embeddedness of co-creation in urban-planning policies to embrace a user-centered approach and to co-designing approach often happens in a spatial medium, the so-called Urban Living Labs (ULLs). Those ULLs are the "enabling environment" whereas the participation-conceptualized as co-design instead-focuses on including diverse forms of knowledge generation in urban- governance processes to create inclusive solutions (da Cruz et al. 2019; Lund 2018). Nesti (2018) iterates on the co-production of services' peculiarities occurring differently based on the service itself. For instance, in some ULL contexts the innovation originates mainly during the co-design stage. While in others, innovation embraces different co-delivery stages as well (e.g., cobuilding or co-maintenance); that stem mainly from the nature of the ULL itself and the approach to public-service innovation.

From a practical perspective, these values of co-creating better and more innovative solutions have a wider impact on problem-solving in a spatial ULL context, by taking a progressive approach towards co-identifying a problem or need and co-ideating, co-designing and co-implementing a solution to it, in addition to comaintenance aspects. ULLs are not a new phenomenon anyway. They have been defined by many scholars as the real-world laboratories for experimental research with edges between research institutions, society, and public authorities. Hence, Living Labs encompass societal and technological dimensions simultaneously in a business-citizen-government-academia partnership (Bulkeley et al. 2018; Menny et al. 2018). Some scholars particularly grasp ULLs as "spatially embedded sites for co-creation of knowledge and solutions by conducting local experiments" (Puerari et al. 2018: 2).

This type of spatial configuration enables experimentation for engagement instruments leading to social urban innovation; the idea of complete co-creation is to offer space for adaptive multi-actor learning and collaborative environment and to enable progressive urban transition (Bulkeley et al. 2016; Evans 2019; Evans and Karvonen 2011; Voytenko et al. 2016). Moreover, the academic literature reports the lessons learned from co-creation experiences in various ULLs applied over a wide spectrum of sectors: mobility, sustainability, food security, natural risks, and others.... ${ }^{2}$

\footnotetext{
${ }^{2}$ Among others, these projects: Looper Project, Sunrise, MUV, and Cities4people.
} 


\section{Methodology: Sewing the Co-creation Pathway and Urban Living Labs Establishment for NBS Implementation}

Setting out the framework of what is meant by co-creation of NBS is challenging. Sewing the bits and pieces of an environmental concept such as NBS with a fluid concept such as co-creation requires: (1) an extensive (and exhaustive) literature review; (2) cross-cutting case-study analysis; and (3) a close monitoring to the current European projects and advancements of urban-planning policies. This paper triangulates data from literature analysis, project materials, and lastly a cross-case study comparison. However, few scientific references bring together both concepts of NBS and co-creation, mainly because the topic is fairly new to the research world, and few implementation experiences have accrued so far.

In Fig. 1, we represent the conceptualization of the complete co-creation environment resulting from the Clever Cities experience. In this figure, we sum up the main concepts originating from the theoretical framework with the methodological corresponding aspects as practiced in Clever Cities co-creation pathway and operational structure through the CALs. The co-creation environment enforces two mains concepts: a medium and a flexible operational structure. In urban contexts, the enabling medium for co-creation would be the ULLs, while the operational structure corresponds to the co-creation pathway that infuses reflection, production, evaluation, and re-adaptation into the process. Accordingly, Clever Cities translates these two concepts introducing: on one hand, the UIP and the CALs as the medium to operate in the spatial context, and the Clever Co-creation pathway (Mahmoud and Morello 2019) as the flexible operational structure, on the other hand.

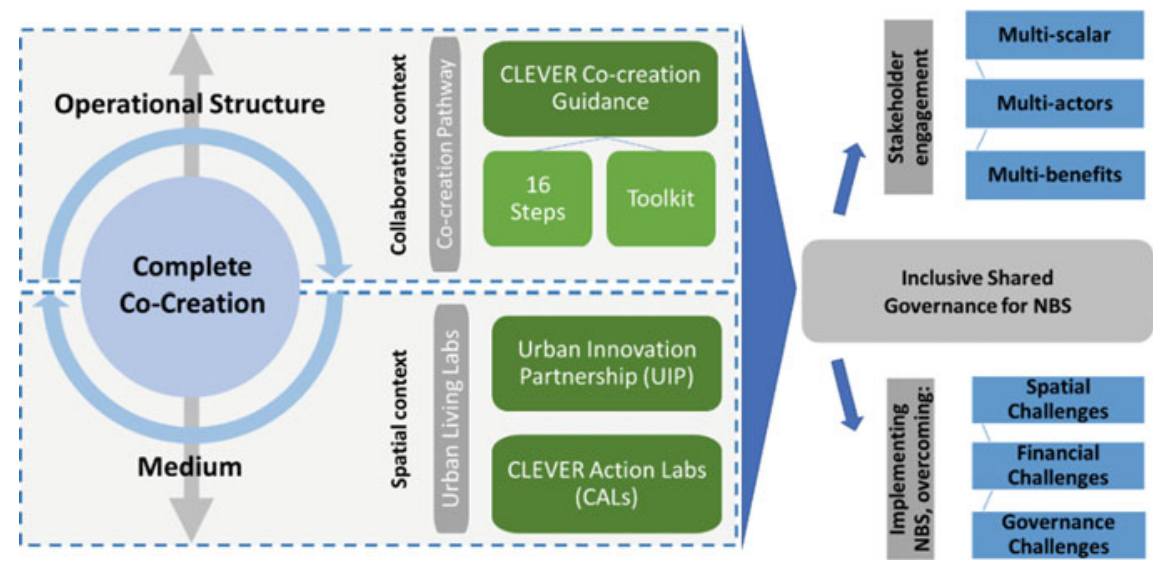

Fig. 1 Concept of the complete co-creation for NBS implementation that integrates the co-creation pathway (the operational structure) and the Urban Living Lab (the spatial medium) 
The Urban Innovation Partnership and the Clever Action Labs, as two main examples of the mechanisms to implement NBS in urban processes, work at different scales, respectively, the urban level and the project-site level. The UIP activates stakeholders at the urban scale, involving them in high-level governance and lobbying for promoting city-wide greening policies and practices. On the other side, CALs operate at the local level in the spatial domain for the tangible co-creation of NBS.

In fact, NBS implementation requires a strong shared-governance approach. Involving a multiplicity of stakeholders aims at attracting a multitude of resources and assets (e.g., financial, human skills, equipment, time, and space availability), achieving a true sense of belonging and adoption of NBS in the urban context. This is not a one-day or tactical urbanism expected result process; on the contrary, to put NBS into place, a sense of co-maintenance and co-management by all stakeholders is recommended (Calliari et al. 2019). In this study, we argue that the spatial, financial and social inclusiveness challenges around NBS could eventually be overcome through the effective involvement of stakeholders and gradual positive impacts generated from the co-benefits resulting from NBS in loco over the long term.

As operational structure, a complete co-creation approach is encouraged to activate the long-term maintenance of NBS after these have been implemented later. Many academics and urban practitioners reveal the lack of guidelines and toolkits to meld both concepts together in a feasible implementation and evaluation frameworks for cities authorities to grasp. The theoretical frameworks of analysis were not holistically approached to embed the stakeholders' collaboration and engagement as an iterative, inclusive, and shared-governance process. The need for integration between NBS challenges and putting co-creation methodologies into practice seemed legitimate. We touch base on the implementation of co-creation in urban-planning practices; as well as, introducing the experience of how the application of co-creation in Clever Cities projects using a pathway for NBS implementation in nine ULLs.

To sum up, the co-creation pathway as a reflection to the operational structure of NBS implementation has been established as a methodological framework (refer to the Clever Cities Co-Creation Guidance 3 by (Morello et al. 2018)) encompassing six phases as follows: UIP establishment, co-creation planning, co-design, co-implementation, co-monitoring, and co-development.

Specifically, the phases are composed of 16 steps, not necessarily consecutive nor synchronous. The structure is intended to be flexibly handled within different urban contexts. These steps are furnished with a variety of recommended, optional, and fundamental tools that help cities establish a complete co-creation process taking in consideration the different spatial place-based contexts, the type of NBS interventions and the governance model selected by the responsible authority. Sleeve toolkits for the co-design, co-implementation, and co-maintenance of NBS are developed with cities to be used as a reference in their progressive co-creation process. The provided guidance documents aim to better articulate the co-creation processes that shape the implementation of NBS in its most effective way. The guidance efficiency

\footnotetext{
${ }^{3}$ see https://guidance.clevercities.eu/ and https://clevercitiesguidance.wordpress.com/co-creationp athway/.
} 
for the cities is currently being monitored through online surveys and face-to-face workshops with local cities teams. The co-creation pathway and guidance in Clever Cities projects are intended as a support methodological tool for open innovation, in which ideas are shared, closely connected to user-generated content and actively communicated to the wider public in order to embed originality and achieve effective governance.

\section{Discussion: A Comparative Study of Nine Action Labs in Three Cities}

Since June 2018, three cities (Hamburg, London and Milan) have been on the forefront of implementing NBS by applying the co-creation pathway, through up-running nine urban living labs as part of diverse urban-regeneration processes. The main involvement of stakeholders in the co-creation process occurs through the phases of co-design and co-implementation. From July 2019 until June 2020, the cities are conducting local workshops with citizens where they work hand-in-hand with local administrations and facilitators to raise awareness of NBS, co-produce interventions and identify the expected co-benefits in a specific CAL context. During the co-implementation phase, they work more on synthetizing and merging stakeholder capacities, funds and overcoming limitations in the CAL-specific status quo and check with specialists the feasibility of the NBS in place.

In this section, an overview analysis of the CALs' experience has been elaborated based our analysis on a comparative study mainly from the official deliverables of the project, such as D2.1: Urban Innovation Partnership establishment (December 2018); D2.2: co-creation planning, and co-design of solutions (June 2019); and D2.3: co-implementation planning (November 2019). To complement the data acquisition, we conducted multiple site visits, regular monthly teleconference calls with cities leaders, bimonthly steering group meetings and interviews with the main local cluster partners.

Grounded in a comparative analysis of these three cities and nine living labs, the key characterization of the NBS implementation framework could be categorized into several key topics as follows:

Firstly, all the three greening strategies target social challenges in neighborhoods contexts with social cohesion problems and undergoing urban regeneration. Hence, NBS are intended as a medium to catalyze attention and interest by citizens, to test collaboration and to build local identity. According to project partners' co-creation workshops, the envisioned measures have been selected to have an impact mainly on human-centered aspects, such as social inclusion, safety and security and wellbeing and only to a lesser extent on environmental quality, biodiversity and climatechange mitigation since they are considered as NBS spillovers in place. In particular, to respond to the situated challenges, each city applies an NBS of different types and at different scales. For instance, Hamburg opted for a green corridor with 
spots-scaled interventions on a cross-neighborhoods ULL; London is working on a water-body intervention in Thamesmead Lake on a whole neighborhood ULL; and Milan promotes punctual interventions along a railway infrastructure and a green roofs and walls in the southern transect of the city. Secondly, most of the selected NBS are small- to medium-scale applications, cheap or of medium cost and potentially easy to implement and be managed by local people within existing community initiatives. Among the most diffused NBS to be co-developed with citizens, we can list raised-bed gardens, nano-gardens to be installed in private balconies and smallscale aquaponics solutions in school yards. More technically demanding NBS from a financial and construction point of view, like green walls and noise barriers, green roofs and phytoremediation, are instead implemented by public or private actors, in the quality of the owners of the NBS measures while co-management is given to citizens. Henceforth, opening the co-creation of these cost-intensive solutions to the wide public is a way to increase their social local acceptance, sense of belonging to the measures in place, and shared outcomes achievement.

Thirdly, it was important to recognize the specific room for maneuver in promoting co-creation as part of the collaborative pathway within each CAL and for each proposed NBS: for instance, some measures cover the complete co-creation pathway, including citizens from ideation to construction and co-management; other NBS, on the contrary, can only allow consulting citizens in the early stage of ideation and engage them in the maintenance at the end. Based on the NBS types and the corresponding co-creation potential, different custom-made governance models have to be established. In fact, in Hamburg, the large-scale green corridor foreseeing multiple NBS in schools and public-owned spaces, requires a strong public authority-driven coordination; in London, the role of Peabody, the social housing property manager is crucial to engage residents, facilitate the collaboration, and provide the right instruments to achieve implementations; in Milan, the variety of the three CALs' objectives require very different governance models, some led at the city level for promoting the engagement of private property owners to install green roofs and walls, some others led by co-creation facilitators at the community level to cope with the complexity and priorities of local people, also in relation to the specific financing mechanisms and co-management options of the proposed NBS.

Grounded in this overview of the local contexts, the following analysis summarized in Table 1, specifically addresses spatial, governance, and financial challenges occurring in the various contexts.

The most connoted differences between the three cities are the urban spatial domains embedding the NBS interventions and the CALs. In fact, some CALs refer to local areal interventions (a new park, a public square, a schoolyard), while some are small-scale measures and diffused over the district (nano-gardens on balconies) or even the whole city (green roofs and walls). Moreover, within the same CAL, several NBS can be co-created and put in place, for instance, within the same public garden.

Therefore, depending on the scale of the NBS, the involvement of the citizens in ideation, construction and maintenance can vary significantly, thus impacting the shared-governance potential. Moreover, the target users and stakeholders involved 
Table 1 Summary of the spatial, governance, and financial challenges addressed by the CLEVER Action Labs

\begin{tabular}{|c|c|c|}
\hline Topics & Strong influences & Weak/negative influences \\
\hline \multicolumn{3}{|l|}{ Spatial challenges } \\
\hline Urban scale of intervention & $\begin{array}{l}\text { Hamburg: opted for a single district } \\
\text { green corridor, unifying efforts on } \\
\text { stakeholder's engagement and } \\
\text { collaboration } \\
\text { London: used a "hybrid solutions" } \\
\text { model for a classic district } \\
\text { urban-regeneration process for } \\
\text { testing the co-creation of NBS } \\
\text { methodology feasibility and } \\
\text { economic viability }\end{array}$ & $\begin{array}{l}\text { Milan has fragmented ULLs } \\
\text { of interventions which } \\
\text { require more "diversity" of } \\
\text { stakeholders and further } \\
\text { collaboration beyond one } \\
\text { CAL-specific scale } \\
\text { All: large-scale } \\
\text { interventions require } \\
\text { long-term maintenance; the } \\
\text { co-implementation plans of } \\
\text { the nine CALs are } \\
\text { developed to include } \\
\text { sections on long-term } \\
\text { maintenance }\end{array}$ \\
\hline Type of interventions & $\begin{array}{l}\text { Hamburg: a diversity of solutions in } \\
\text { school yards and green roofs enable } \\
\text { a variety of co-benefits spreading } \\
\text { Milan: a new train stop embedding } \\
\text { green walls and noise barriers and a } \\
\text { green public living space as an } \\
\text { open-air waiting room for } \\
\text { commuters }\end{array}$ & $\begin{array}{l}\text { Milan: a variety of types of } \\
\text { interventions, which makes } \\
\text { the prioritization of specific } \\
\text { NBS in place a hard process } \\
\text { in co-design } \\
\text { All: Integration of CALs in } \\
\text { existing urban contexts is } \\
\text { noticeably slow because } \\
\text { citizen engagement is } \\
\text { happening in a gradual } \\
\text { involvement process }\end{array}$ \\
\hline Maintenance and upscaling & $\begin{array}{l}\text { All: Possible success stories in EU } \\
\text { contexts due to citizens' } \\
\text { stewardships (e.g., in London) } \\
\text { Hamburg: educational aspects and } \\
\text { awareness raised for school } \\
\text { students and possible future } \\
\text { interventions }\end{array}$ & $\begin{array}{l}\text { All: Lack of financial } \\
\text { resources due to long-term } \\
\text { feasibility models that } \\
\text { require return of investment } \\
\text { in sustainable planning } \\
\text { All: Citizen stewardship } \\
\text { tested against the } \\
\text { co-creation process and } \\
\text { requires long-term } \\
\text { involvement of stakeholders }\end{array}$ \\
\hline Environmental benefits & $\begin{array}{l}\text { London: The lake to be regenerated } \\
\text { and reclaimed, hence enhancing } \\
\text { biodiversity } \\
\text { Hamburg: Social cohesion with } \\
\text { schoolyards project and raised-bed } \\
\text { gardens } \\
\text { Milan: less noise pollution and a } \\
\text { new community garden in } \\
\text { Giambellino area }\end{array}$ & $\begin{array}{l}\text { Milan: possible green } \\
\text { gentrification from green } \\
\text { roofs and walls lab } \\
\text { Hamburg: low impact from } \\
\text { green roofs labs due to } \\
\text { small-scale intervention } \\
\text { London: possible green } \\
\text { gentrification from lake } \\
\text { cleaning and NBS social } \\
\text { segregation }\end{array}$ \\
\hline
\end{tabular}


Table 1 (continued)

\begin{tabular}{|c|c|c|}
\hline Topics & Strong influences & Weak/negative influences \\
\hline \multicolumn{3}{|l|}{ Governance challenges } \\
\hline $\begin{array}{l}\text { Urban policies and } \\
\text { regulations }\end{array}$ & $\begin{array}{l}\text { Hamburg opted for digital } \\
\text { participation for citizen } \\
\text { engagement in the process } \\
\text { London: overcome the low } \\
\text { participation from local citizens } \\
\text { with school students } \\
\text { Milan: CAL } 1 \text { embedding } \\
\text { co-creation procedure involving } \\
\text { stakeholders (municipality, } \\
\text { professionals and citizens) as part } \\
\text { of the public bid for green roofs } \\
\text { and facades as a prerequisite to } \\
\text { access funding }\end{array}$ & $\begin{array}{l}\text { All: many assessment } \\
\text { frameworks and procedural } \\
\text { inequalities that a specific } \\
\text { pathway for implementation } \\
\text { does not necessarily work } \\
\text { equally } \\
\text { - No specific guidelines on } \\
\text { how NBS should be } \\
\text { co-created and up-scaled in } \\
\text { urban contexts; the } \\
\text { co-creation guidance was } \\
\text { the first experience to guide } \\
\text { the process development }\end{array}$ \\
\hline $\begin{array}{l}\text { Urban Innovation } \\
\text { Partnership }\end{array}$ & $\begin{array}{l}\text { London: inclusive process by } \\
\text { bringing on board citizens, } \\
\text { residents, environmental agencies, } \\
\text { and local government authorities. } \\
\text { Milan: innovation to embed } \\
\text { co-creation in a municipal } \\
\text { governance process }\end{array}$ & $\begin{array}{l}\text { Milan: fragmentation of } \\
\text { resources between public } \\
\text { and private authorities } \\
\text { which requires longer times } \\
\text { to overcome the breaking- } \\
\text { siloes process, defined as } \\
\text { path-dependency processes }\end{array}$ \\
\hline $\begin{array}{l}\text { Management and } \\
\text { monitoring }\end{array}$ & $\begin{array}{l}\text { London: potential usage of smart } \\
\text { applications already in the market } \\
\text { to measure the success of social } \\
\text { cohesion in the area, safety and } \\
\text { security }\end{array}$ & $\begin{array}{l}\text { Hamburg: Lack of adequate } \\
\text { framework for assessment } \\
\text { of NBS impacts of social } \\
\text { cohesion (in general) and } \\
\text { specific measures to } \\
\text { inclusion }\end{array}$ \\
\hline $\begin{array}{l}\text { Communication and } \\
\text { transparency }\end{array}$ & $\begin{array}{l}\text { Milan: periodic newsletter sent to a } \\
\text { network of stakeholders for events } \\
\text { and participation } \\
\text { All: cross-cutting collaboration and } \\
\text { information circulation between } \\
\text { PM and all involved partners due to } \\
\text { shared digital platforms }\end{array}$ & $\begin{array}{l}\text { Different Language in } \\
\text { Hamburg and Milan made } \\
\text { the communication with the } \\
\text { public harder due to } \\
\text { translation of NBS materials } \\
\text { All: benchmarking } \\
\text { CLEVER CALs is } \\
\text { challenging to communicate } \\
\text { in the same way to local } \\
\text { agencies and citizens }\end{array}$ \\
\hline \multicolumn{3}{|l|}{ Financial challenges } \\
\hline $\begin{array}{l}\text { Installation, maintenance, } \\
\text { and type of intervention }\end{array}$ & $\begin{array}{l}\text { All: the difference in spatial scales } \\
\text { of NBS interventions make the } \\
\text { financial investment vary by } \\
\text { consequences. In other words, the } \\
\text { commitment to co-maintain the } \\
\text { solution varies by the type of social } \\
\text { responsibility, as well }\end{array}$ & $\begin{array}{l}\text { All: risk of lack of wider } \\
\text { citizen engagement in ULLs } \\
\text { and co-design processes. } \\
\text { Engagement through } \\
\text { volunteering or in-kind } \\
\text { compensations in general }\end{array}$ \\
\hline
\end{tabular}


Table 1 (continued)

\begin{tabular}{l|l|l}
\hline Topics & Strong influences & Weak/negative influences \\
\hline Securing long-term funds & $\begin{array}{l}\text { Milan: public and private funding } \\
\text { opportunities on a public bid for } \\
\text { promoting green roofs and walls, } \\
\text { with extra 10\% on-top increment in } \\
\text { case of implementing innovative } \\
\text { solutions }\end{array}$ & $\begin{array}{l}\text { Milanticulties to } \\
\text { implement a financing } \\
\text { scheme in public tenders } \\
\text { that enables embedding } \\
\text { co-designed interventions }\end{array}$ \\
\hline
\end{tabular}

the co-creation (e.g., citizens in general, school pupils, social housing residents) affect the medium of the CALs, ranging from a variety of in-presence activities (focus groups, public events, contests) to online participatory tools (surveys, social media groups, and debates). In addition to the modalities to engage stakeholders, collaborative decision-making requires public authorities to incorporate the sharedgovernance attitude into routine planning procedures, breaking the silos of traditional decision making. Moreover, co-creation of NBS requires robust maintenance and a monitoring cultural approach, particularly essential when dealing with evolving living green features.

Finally, financial challenges also depend on the scale of intervention, the type of stakeholders involved and the owners of NBS, either public or private. For instance, a hard infrastructure like a green noise barrier or a lake-wide phytoremediation requires concentrated investment, often based on consolidated procedures, like public tenders. In fact, embedding co-design interventions in public procurement procedures has turned out to be one of the most crucial challenges that requires the implementation of innovative financing schemes. On the other hand, diffusing small-scale NBS among citizens can be based on public incentives (e.g., a public tender for funding green roofs) or happen at no cost, when exclusively relying on people voluntary contribution (i.e., nano-gardens on balconies).

\section{Conclusions and Bottlenecks: Lesson Learned from Experiences of Implementing Co-created NBS in Cities}

Relying on real on field experience carried out in the aforementioned European cities, this paper investigates the major challenges encountered during the implementation of a co-creation pathway for embedding NBS in urban-regeneration processes in the three front-runner cities. Beyond these three cities, the project has six fellow cities that follow the co-creation pathway and are setting up their ULLs at a later stage. The evidence about experimental indicators for success of the co-creation process is the knowledge transfer between cities and lessons learned during the process. However, the project is still in its first two years, which gives space to iterate on the process and periodically inform the lessons learnt. The ultimate goal of this study 
is to understand if it is possible to move from siloes thinking and decision-making routines to experimental co-creation experiences, adopting more consolidated and shared-governance routines and participatory practices in urban policies at city level.

Since the integration of NBS in the urban context comprises a variety of typologies, scales of applications and sizes, ULL types and actors involved, the question is if it is possible providing a universal, comprehensive and at the same time flexible cocreation approach to meet all these conditions under the bigger umbrella of a holistic urban-greening strategy. Elaborating on these questions, the study investigates the current ongoing co-creation experiences of nine living labs, resulting on the major issues and challenges, as summarized below.

(1) Localizing NBS into urban-regeneration context of ongoing processes: exploring how NBS interventions enter the narrative of urban-planning strategies at city and local level; how cities are providing a solid vision and mission for mainstreaming urban-greening projects. Most of the times, NBS projects overlap with ongoing urban dynamics. In some cases, NBS are assumed to be an occasion to accelerate urban transition; in other cases, NBS do not meet societal priorities in specific contexts, whereby urban greening is not always recognized as a key topic when it comes to allocating limited economic resources.

The lesson learned is to introduce NBS as a key city-wide urban-regeneration priority action from the very beginning, hence ensuring that the co-benefits are highlighted to stakeholders and end-users during the whole decision-making process and not just as the result of a greening intervention. This will ensure a wider sense of belonging and ownership.

(2) Communicating NBS to wider society public: by definition, NBS should aim to address specific environmental and social challenges that are place-based. We examined if this is always the case, and if people perceive the role of NBS effect in providing those expected co-benefits. For instance, it is not easy to communicate and acquire evidence of the wider role NBS can play. The translation of the technical term of NBS into practice, i.e., its common use as a concept in participatory activities, is questionable. In fact, the term, originated in academic and research domains, is hardly transferable to the wider public during engagement processes.

The lessons learned is hence to build a strong network that can diffuse NBS culture to a wider audience through a consolidated partnership, whereas the supply and demand for greening services are dialoging, communicating and constantly collaborating and simplifying its dissemination.

(3) Homogenizing approaches for different NBS interventions: NBS have revealed to be extremely varied terms of typologies and operation at different scales. This variety makes a universal approach to co-creation rather uncertain. For instance, stressing participatory approaches and the involvement of a multitude of actors, in the implementation of very small-scale interventions, might waste resources, especially in fragile urban contexts. On the contrary, high-impact large-scale NBS infrastructure can only hardy be shared with the wider public. 
The lesson learned is to use innovative tools of co-creation (like co-design by immersion, personas simulation and digital participation tools) to facilitate and speed-up the implementation of complex large-scale NBS with limited timespan and flexibility.

(4) Attracting investments: The attraction of financial investment around NBS follows very complex patterns. Interpreting actors' constraints in the absence of a direct and tangible return of investment and investigating how cities try to provide effective stimuli are crucial aspects of successful NBS implementation. Financial issues refer in particular to both the implementation and the long-term co-management of NBS and the need for new business models in urban nature stewardship.

The lessons learned is that incurring multiple stakeholders' involvement through an urban partnership and the establishment of a strong city-wide vision and narrative of NBS role in the overall greening strategy is crucial, in order to support the consolidation of a strong economic long-term investment.

(5) Enabling shared governance in public authorities' routines: Finally, the overall capacity of a city administration to provide a reliable and consolidated framework for enabling a shared governance and an effective and continuous participation process consistent with the NBS co-creation pathway remains the main challenge in the background of this study. This work examined: if cities are able to translate experimental processes into policies; if cities are gearing up to make co-creation practices a routine into all urban-greening interventions; and if cities are embedding co-creation sleeve tools and updating urban-planning policies and bureaucratic procedures to make co-creation easier.

The lessons learned is that embedding co-creation into decision-making routines is still a challenge and requires to overcome practical obstacles, among others: breaking siloes in decision-making procedures, managing the costs of continuous day-to-day activity of back-and-forth dialogue between owners, authorities, and stakeholders, which is demanding in terms of effort, time and money. People responsible for NBS implementation tend to avoid sharing decisions with the public to reduce conflicts and delays. If applied from the very beginning and with all the stakeholders, co-creation can give a boost to regeneration processes, but it requires skills in facilitation public participation and co-creation.

To sum up, although NBS are lately gaining a widespread consensus among researchers and are supported by the European Commission funding schemes with a remarkable outreach, there is a further need to formalize their impacts and potentials with a multitude of actors and implementation mechanisms, taking into account the variety of NBS types, scales and applications situations. Bringing the process inside local authorities' headquarters, municipality seats and public or private organizations was shown to be rather challenging. Nonetheless, it is doubtless that citizen engagement in urban-planning processes has become more diffused, structured, and institutionalized, especially through these pilot projects. However, co-creation of NBS is still perceived—and often applied—as a fuzzy concept and time-consuming 
task. More research is needed to enable co-creation to be embedded deeper into ordinary planning processes.

Acknowledgements This document has been prepared in the framework of the European project CLEVER Cities. This project has received funding from the European Union's Horizon 2020 innovation action program under grant agreement no. 776604 . The sole responsibility for the content of this publication lies with the authors. The authors would like to thank Dr. Carolina Cantergiani De Carvalho from Tecnalia team; the project coordinator, Dr. Martin Krekeler, from HWWI; Emilia Barone, Nicola-Murphy Evans and Jan Pastoors, city project managers of Milan, London, and Hamburg, respectively, for their work on the coordination of the co-creation process in cities and the provision of documents and project deliverables.

The authors would like to thank the two anonymous reviewers for their valuable comments and contribution to improve the quality of the manuscript in its final form.

\section{References}

Agrawal AK, Kaushik AK, Rahman Z (2015) Co-creation of Social value through integration of stakeholders. Procedia Soc Behav Sci 189:442-448. https://doi.org/10.1016/j.sbspro.2015.03.198

Albert C, Schröter B, Haase D, Brillinger M, Henze J, Herrmann S et al (2019) Addressing societal challenges through nature-based solutions: how can landscape planning and governance research contribute? Landsc Urban Plan 182(September 2018):12-21. https://doi.org/10.1016/j. landurbplan.2018.10.003

Bason C (2010) Leading public sector innovation: co-creating for a better society. MindLab, 1-278

Bason C (2013) Powering European Public Sector innovation: towards a new architecture. European Commission, Luxembourg. https://doi.org/10.2777/51054

Bisschops S, Beunen R (2019) A new role for citizens' initiatives: the difficulties in co-creating institutional change in urban planning. J Environ Planning Manage 62(1):72-87. https://doi.org/ $10.1080 / 09640568.2018 .1436532$

Bourguignon D (2017) Nature-based solutions Concept, opportunities and challenges

Bulkeley H, Coenen L, Frantzeskaki N, Hartmann C, Kronsell A, Mai L et al (2016) Urban living labs: governing urban sustainability transitions. Curr Opin Environ Sustain 22:13-17. https://doi. org/10.1016/j.cosust.2017.02.003

Bulkeley H, Marvin S, Palgan YV, McCormick K, Breitfuss-Loidl M, Mai L et al (2018) Urban living laboratories: conducting the experimental city? Eur Urban Reg Stud. https://doi.org/10. $1177 / 0969776418787222$

Burkett I (2016) An introduction to co-design/co-designing for social good: the role of citizens in designing and delivering social services, Part One

Calliari E, Staccione A, Mysiak J (2019) An assessment framework for climate-proof nature-based solutions. Sci Total Environ 656:691-700. https://doi.org/10.1016/j.scitotenv.2018.11.341

Cohen-Shacham E, Andrade A, Dalton J, Dudley N, Jones M, Kumar C et al (2019) Core principles for successfully implementing and upscaling Nature-based Solutions. Environ Sci Policy 98(April):20-29. https://doi.org/10.1016/j.envsci.2019.04.014

da Cruz NF, Rode P, McQuarrie M (2019) New urban governance: a review of current themes and future priorities. J Urban Affairs 41(1):1-19. https://doi.org/10.1080/07352166.2018.1499416

DeLosRíos-White MI, Roebeling P, Valente S, Vaittinen I (2020) Mapping the life cycle co-creation process of nature-based solutions for urban climate change adaptation. Resources 9(29)

Engage2020 (2015) Public Engagement Methods and Tools. Tools and instruments for a better societal engagement in "Horizon 2020" 
European Commission (2015) Towards an EU research and innovation policy agenda for Naturebased solutions and re-naturing cities. https://doi.org/10.2777/479582

Evans J (2019) Governing cities for sustainability: a research agenda and invitation. Front Sustain Cities 1(June):4-7. https://doi.org/10.3389/frsc.2019.00002

Evans J, Karvonen A (2011) Living laboratories for sustainability: exploring the politics and epistemology of urban transition. In: Harriet Bulkeley SM, Broto VC, Hodson M (eds) Cities and low carbon transitions. Routledge , London, pp 126-141. https://doi.org/10.4324/9780203839249

Frantzeskaki N (2019) Seven lessons for planning nature-based solutions in cities. Environ Sci Policy 93(December 2018):101-111. https://doi.org/10.1016/j.envsci.2018.12.033

Frantzeskaki N, Kabisch N (2016) Designing a knowledge co-production operating space for urban environmental governance-lessons from Rotterdam, Netherlands and Berlin, Germany. Environ Sci Policy 62:90-98. https://doi.org/10.1016/j.envsci.2016.01.010

Galafassi D, Daw TM, Thyresson M, Rosendo S, Chaigneau T, Bandeira S et al (2018) Stories in social-ecological knowledge cocreation. Ecol Soc 23(1). https://doi.org/10.5751/ES-09932230123

Gudowsky N, Peissl W (2016) Human centred science and technology—transdisciplinary foresight and co-creation as tools for active needs-based innovation governance. Eur J Futures Res 4(1). https://doi.org/10.1007/s40309-016-0090-4

Jansen S, Pieters M (2017) The 7 principles of complete co-creation, vol. 40. https://doi.org/10. 3724/SP.J.1004.2014.00051

Lafortezza R, Sanesi G (2019) Nature-based solutions: settling the issue of sustainable urbanization. Environ R 172(August 2018):394-398. https://doi.org/10.1016/j.envres.2018.12.063

Lawrence A, De Vreese R, Johnston M, Bosch CC, Sanesi G (2013) Urban forest governance: towards a framework for comparing approaches. Urban For Urban Green 12(4):464-473. https:// doi.org/10.1016/j.ufug.2013.05.002

Leith P, O'Toole K, Haward M, Coffey B, Rees C, Ogier E (2014) Analysis of operating environments: a diagnostic model for linking science, society and policy for sustainability. Environ Sci Policy 39:162-171. https://doi.org/10.1016/j.envsci.2014.01.001

Leroy P, Arts B (2006) Institutional dynamics in environmental governance. Inst Dyn Environ Govern, 1-19. https://doi.org/10.1007/1-4020-5079-8_1

Lund DH (2018) Co-creation in urban governance: from inclusion to innovation. Scand J Public Adm 22(2):3-17

Mahmoud I, Morello E (2019) Co-creation pathway as a catalyst for implementing nature-based solution in urban regeneration strategies learning from CLEVER cities framework and Milano as test-bed. Urbanistica Informazioni 25(278):204-210

Mauser W, Klepper G, Rice M, Schmalzbauer BS, Hackmann H, Leemans R, Moore H (2013) Transdisciplinary global change research: the co-creation of knowledge for sustainability. Curr Opin Environ Sustain 5(3-4):420-431. https://doi.org/10.1016/j.cosust.2013.07.001

McCormick K, Kiss B (2019) Taking action for urban nature: innovation pathway directory. Naturvation Guide, Horizon 2020

Menny M, Voytenko Palgan Y, McCormick K (2018) Urban living labs and the role of users in co-creation. Gaia 27:68-77. https://doi.org/10.14512/gaia.27.S1.14

Morello E, Mahmoud I, Gulyurtlu S (2018) Guidance on co-creating nature-based solutions PART II-running CLEVER Action Labs in 16 steps. Deliverable 1(1):6

Nesti G (2018) Co-production for innovation: the urban living lab experience. Policy Soc 37(3):310 325. https://doi.org/10.1080/14494035.2017.1374692

Parsons M, Fisher K, Nalau J (2016) Alternative approaches to co-design: insights from indigenous/academic research collaborations. Curr Opin Environ Sustain 20:99-105. https://doi.org/ 10.1016/j.cosust.2016.07.001

Pater M (2009) CO-CREATION'S 5 guiding principles (No. 1). Fronteer Strategy

Prahalad CK, Ramaswamy V (2004) Co-creation experiences: the next practice in value creation. J Interact Market 18(3):5-14. https://doi.org/10.1002/dir.20015 
Puerari E, De Koning JIJC, Von Wirth T, Karré PM, Mulder IJ, Loorbach DA (2018) Cocreation dynamics in urban living labs. Sustain Putting Sustain Transit Spat Socio-Cult Context 10(6):1893. https://doi.org/10.3390/su10061893

Ramaswamy V, Ozcan K (2018) What is co-creation? An interactional creation framework and its implications for value creation. J Bus Res 84(November 2017):196-205. https://doi.org/10.1016/ j.jbusres.2017.11.027

Raymond CM, Berry P, Breil M, Nita MR, Kabisch N, de Bel M et al (2017) An impact evaluation framework to support planning and evaluation of nature-based solutions projects. https://doi.org/ 10.13140/RG.2.2.18682.08643

Rock J, McGuire M, Rogers A (2018) Multidisciplinary perspectives on co-creation. Sci Commun 40(4):541-552. https://doi.org/10.1177/1075547018781496

Sanders EB-N, Stappers PJ (2008) Co-creation and the new landscapes of design. J CoDesign 4(1):5-18. https://doi.org/10.1080/15710880701875068

Serrano Sanz F, Holocher-Ertl T, Kieslinger B, Sanz García F, Silva GC (2014) WHITE PAPER on citizen science for Europe. Soientize: Citizen science projects.

TeRRIFICA (2019) Key definitions for the project: co-Creation. https://terrifica.eu/resources/keydefinitions-for-the-project/. Accessed 20 Sept 2019

Voytenko Y, McCormick K, Evans J, Schliwa G (2016) Urban living labs for sustainability and low carbon cities in Europe: towards a research agenda. J Clean Prod 123:45-54. https://doi.org/10. 1016/j.jclepro.2015.08.053

Wippoo M, van Dijk D (2019) D5.1 Toolkit on co-creation process: engaging the public with responsible research and innovation on food security

Open Access This chapter is licensed under the terms of the Creative Commons Attribution 4.0 International License (http://creativecommons.org/licenses/by/4.0/), which permits use, sharing, adaptation, distribution and reproduction in any medium or format, as long as you give appropriate credit to the original author(s) and the source, provide a link to the Creative Commons license and indicate if changes were made.

The images or other third party material in this chapter are included in the chapter's Creative Commons license, unless indicated otherwise in a credit line to the material. If material is not included in the chapter's Creative Commons license and your intended use is not permitted by statutory regulation or exceeds the permitted use, you will need to obtain permission directly from the copyright holder.

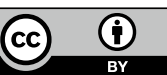

